\title{
Computer vision syndrome in presbyopic digital device workers and progressive lens design
}

\author{
Mar Sánchez-Brau ${ }^{1}$ (D), Begoña Domenech-Amigot ${ }^{2}$ (D) Francisco Brocal-Fernández ${ }^{3,4}$ (D) and \\ Mar Seguí-Crespo ${ }^{2,5}$ \\ ${ }^{1}$ Doctoral Programme in Health Sciences, University of Alicante, Alicante, Spain, ${ }^{2}$ Department of Optics, Pharmacology and Anatomy, University of \\ Alicante, Alicante, Spain, ${ }^{3}$ Department of Physics, Systems Engineering and Signal Theory, University of Alicante, Alicante, Spain, ${ }^{4}$ University Institute \\ of Physics Applied to Sciences and Technologies, University of Alicante, Alicante, Spain, and ${ }^{5}$ Public Health Research Group, University of Alicante, \\ Alicante, Spain
}

Citation information: Sánchez-Brau M, Domenech-Amigot B, Brocal-Fernández F, \& Seguí-Crespo M. Computer vision syndrome in presbyopic digital device workers and progressive lens design. Ophthalmic Physiol Opt 2021; 41: 922-931. https://doi.org/10.1111/opo.12832

Keywords: computer vision syndrome, digital devices, presbyopia, progressive addition lenses, workers

Correspondence: Begoña Domenech-Amigot E-mail address: b.domenech@ua.es

Received: 16 September 2020; Accepted: 16 March 2021; Published online: 4 May 2021

\begin{abstract}
Purpose: To estimate the prevalence of computer vision syndrome (CVS) in presbyopic digital device workers using two ophthalmic progressive lens designs during the working day, and to analyse the association of CVS with sociodemographic, occupational, digital device exposure and refractive factors.

Methods: This time series, quasi-experimental design study included 69 presbyopic digital device workers (age range: $46-69$ years; mean $\pm \mathrm{SD}=54.7 \pm 5.0$ ). All used desktop computers at their workplace. Progressive addition lenses (PALs) and occupational lenses were used for three months each. CVS was measured with the CVS- $\mathrm{Q}^{\odot}$ questionnaire before intervention (baseline) and at 1 week, 1 month and 3 months after wearing the lenses. A multivariate logistic regression model was used to identify the factors that were associated with an improved CVS-Q ${ }^{\circ}$ score.

Results: $37.7 \%$ of the subjects were female and $78.3 \%$ were ametropes; $65.2 \%$ had advanced presbyopia. $56.2 \%$ used digital devices at work $>6 \mathrm{~h} \mathrm{day}^{-1}$. The prevalence of CVS at baseline, after wearing PALs for three months and after three months of occupational lens wear was $68.1 \%, 33.3 \%$ and $18.8 \%$, respectively. The mean CVS- $Q^{\circ}$ score was lower with occupational lenses than with PALs $(p=0.001) .40 .6 \%$ of the digital device workers improved their $\mathrm{CVS}-\mathrm{Q}^{\odot}$ score $\geq 2$ points with the occupational lenses. Ametropes were less likely than emmetropes to improve with occupational lenses ( $\mathrm{OR}=0.27, p=0.05) .89 .8 \%$ of the sample workers were satisfied or very satisfied with the occupational lenses and $71 \%$ were similarly satisfied with the PALs. $73.9 \%$ chose the occupational lenses as their first choice of lens for digital device use, compared with $17.4 \%$ for PALs.

Conclusions: Computer vision syndrome is reduced in presbyopic desktop computer workers wearing occupational lenses compared with PALs, especially in emmetropes.
\end{abstract}

\section{Introduction}

More than half of European workers use digital devices at work, and $37 \%$ use them more than $75 \%$ of the working day. Finance, public administration and education are the economic sectors in which digital device usage is the highest. ${ }^{1}$ This emerging occupational risk is associated with an increase in musculoskeletal disorders, impaired vision and psychological problems. ${ }^{2,3}$

Tasks using digital devices involve intense visual effort and changes in the ocular surface and tear film, generating discomfort. ${ }^{4,5}$ Computer vision syndrome (CVS) is defined as a group of ocular and vision-related problems caused by the prolonged use of digital devices such as 
desktop or laptop computers, tablets, e-readers and cell phones. CVS symptoms may include eyestrain, headache and dryness, among others. ${ }^{6-8}$ In the scientific literature, the prevalence of CVS in workers varies between $20 \%{ }^{9}$ and $80 \% .^{10}$ This variability is attributed to the fact that the studies published so far evaluated CVS through unvalidated, unstructured questionnaires. These often include different symptoms as well as imprecise definitions when considering a worker to be symptomatic, ${ }^{11-15}$ which compromise the findings. The prevalence depends on factors related to task demands, workplace conditions and the visual characteristics of the worker. ${ }^{16,17}$ Furthermore, age, being female or wearing contact lenses can also increase symptoms. ${ }^{18-21}$

Individuals with presbyopia have special visual limitations in the use of digital devices, due to their reduced accommodative capacity. Progressive addition lenses (PALs) provide presbyopes with good vision at any distance, while occupational lenses are modified PALs that have been developed for high intermediate-vision demands coupled with higher near-vision requirements. Several occupational lenses have been designed for computer users and often called progressive computer lenses. ${ }^{22}$ The optical advantages of the latter are evident, given that smaller lateral aberrations ensure wider visual fields (larger intermediate zones). ${ }^{14}$ However, the subjective aspects perceived by workers, i.e., the level of symptoms reported with the different progressive designs should be also considered. Studies that have addressed this issue are scarce and have important limitations that compromise their results. Limitations include not using validated questionnaires to measure CVS, not excluding workers with ocular disease or who are undergoing eye treatment or comparing workers with different working conditions. ${ }^{14,23-25}$

In an attempt to overcome these limitations, the objective of this study is to estimate the prevalence of CVS in a sample of presbyopic workers who use digital devices using two ophthalmic progressive lens designs during the working day, and to analyse the association of CVS with sociodemographic, occupational, digital device exposure and refractive factors.

\section{Methods}

\section{Study design}

This is a time series, quasi-experimental design of two interventions. The study was carried out between April and November 2018 at the University of Alicante (UA), Spain. The measurements were conducted at seven time points: a baseline measure with their usual spectacles (T0), at 1 week (T1), 1 month (T2) and 3 months (T3) after PAL adaptation, and at 1 week $\left(\mathrm{T}^{\prime} 1\right), 1$ month $\left(\mathrm{T}^{\prime} 2\right)$ and 3 months $\left(\mathrm{T}^{\prime} 3\right.$ ) after occupational lens adaptation (Figure 1). The statement of Transparent Reporting of Evaluations with Nonrandomized Designs (TREND) was used as a guide in this study to ensure high design quality. ${ }^{26}$

\section{Subjects and ethics}

From the population of 1934 workers older than 45 years of age at the University of Alicante, a representative sample of 68 people was calculated using the software $\mathrm{G}^{*}$ Power 3.1 (gpower.hhu.de). ${ }^{27,28}$ This calculation was performed assuming a significance level of alpha of 0.05 and a power of $95 \%$ in one group and seven repeated measures over time. An effect size of 0.15 and a correlation among repeated measures of 0.5 were also considered. To compensate for possible losses to follow-up (10\%), 75 workers were included.

Workers who used a computer for more than four hours during their working day for at least five days per week, ${ }^{29}$ habitual users of PALs in the workplace (to minimise the adaptation period) and individuals with corrected binocular visual acuity (VA) at far and near of $0.0 \log$ MAR or less were included. Individuals who wore contact lenses, had ocular surgery, ocular pathology or ocular/systemic treatment in the 3 months before the study, occupational lens wearers and those whose work required them to attend to the public (where occupational lenses would hinder their ability to work comfortably) were excluded.

E-mail was used to provide information about the study and the inclusion/exclusion criteria. A random selection was made of workers who expressed an interest in participating. All workers signed an informed consent.

The study was approved by the University Ethics Committee (UA-2017-09-13) and was conducted following the standards of good clinical practice and international ethical principles applicable to human research according to the latest revision of the Declaration of Helsinki. In addition, the Organic Law 3/2018, December 5, of personal data protection and guarantee of digital rights (Spain) was considered.

\section{Characteristics of the ophthalmic lenses}

The PALs used were the Union-Optic V-PRO Plus (unionoptic.gr), while the occupational lenses were the UnionOptic iOffice (union-optic.gr) providing clear vision at a maximum distance of $2 \mathrm{~m}$ and near vision at $40 \mathrm{~cm}$. All lenses used freeform manufacturing technology on the back surface. They had a refractive index of either 1.5 or 1.6 (from $-3.00 \mathrm{D}$ in distance vision), with anti-reflective and hard coating, UV protection $\leq 380 \mathrm{~nm}$ and three different progression corridor lengths $(14,16$ and $18 \mathrm{~mm})$ depending on the fitting parameters. 


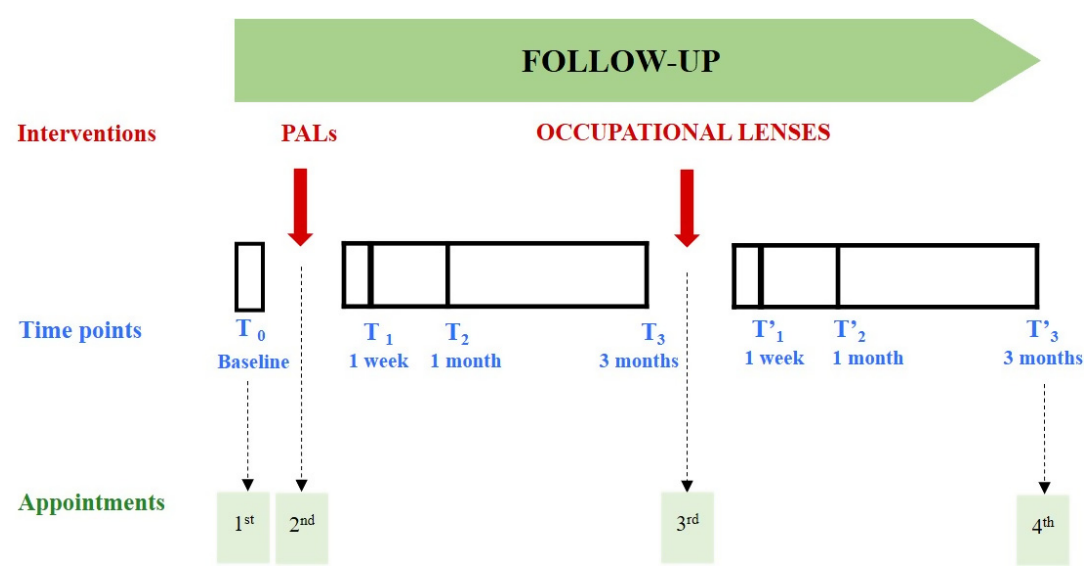

Figure 1. Study design. PALs: progressive addition lenses.

\section{Clinical procedure and intervention allocation}

At the first appointment, an initial anamnesis was performed with questions about age, sex, ocular and systemic history. Likewise, occupational category (AS: administrative staff or TRS: teaching and research staff) and information regarding exposure to digital devices (use in the workplace: hours/day, days/week, years, maximum continuous time, scheduled breaks and use for leisure) were collected. The usual spectacles of each worker were measured with a Visionix VX40 lens analyser (luneautechusa.com). Non-cycloplegic refraction was performed using retinoscopy followed by subjective refraction, and monocular and binocular VA was measured at far and near $(40 \mathrm{~cm})$ distances. Refractive error ( $S$ : sphere, C: cylinder, $\alpha$ : axis) was transformed into power vectors (M: equivalent sphere, $\mathrm{J}_{0}$ and $\mathrm{J}_{45}$ Jackson cross-cylinders), and the overall defocus (overall blurring strength) was calculated using the following formula ${ }^{30}: \mathrm{B}=\left(\mathrm{M}^{2}+\mathrm{J}_{0}{ }^{2}+\mathrm{J}_{45}{ }^{2}\right)^{1 / 2}$. Each participant's spherical equivalent was considered as the mean $\mathrm{M}$ value of the two eyes. Workers were classified as emmetropes when the mean $\mathrm{M}$ was $>-0.75 \mathrm{D}$ and $<+1.0 \mathrm{D}$; the remainder were classified as ametropes. ${ }^{31}$ Workers with additions $\leq 2 \mathrm{D}$ were considered as moderate presbyopes, and those with near additions $>2$ D were considered advanced presbyopes. Anisometropia was considered as a difference in the spherical equivalent between the two eyes $\geq 1 \mathrm{D} \quad(1.00-$ $1.99 \mathrm{D}$ mild, $2.00-2.99 \mathrm{D}$ moderate and $\geq 3.00 \mathrm{D}$ severe anisometropia). ${ }^{32-34}$ The workers chose frames according to their facial features, and centres and pupillary heights were measured using the Essilor Visioffice (essilorpro.com).

At the second appointment, PALs were provided and subjects were instructed to always use them at the workplace (both for the computer and for all working tasks) for the following three months. After this period, the workers returned for a third appointment and occupational lenses were provided (glazed into the same frame) for a further three months. At that time, subjects were informed that the occupational lenses could present difficulties with some distance vision tasks such as driving. A researcher (MSB) randomly visited the workplaces in order to monitor compliance with the instructions.

At the fourth appointment, workers completed an ad hoc satisfaction survey that addressed three issues: the level of satisfaction with each lens during digital device use, the time needed to adapt to the lenses and the lens preference for digital device use, while also justifying their answer.

At the end of the study, the two pairs of lenses and the frame were delivered to the workers at no charge.

\section{Measurement of computer vision syndrome (CVS)}

Computer vision syndrome was measured using the Computer Vision Syndrome Questionnaire (CVS-Q ${ }^{\mathscr{C}}$ ) in digital form, which was sent by e-mail at baseline (T0); at 1 week, 1 and 3 months after wearing PALs (T1, T2 and T3) and after wearing the occupational lenses $\left(T^{\prime} 1, T^{\prime} 2\right.$ and $\left.T^{\prime} 3\right)$. This is a validated and self-administered questionnaire that evaluates the frequency and intensity with which 16 symptoms are perceived over time with digital device use. Using these data, a severity score is calculated for each symptom, and a final score obtained. If the score is $\geq 6$, the worker suffers from CVS. The CVS-Q ${ }^{\mathcal{O}}$ has acceptable psychometric properties derived from the Rasch analysis, with sensitivity and specificity values of $75.0 \%$ and $70.2 \%$, respectively. This makes it a valid and reliable tool to assess the visual health of digital device workers which can be used in clinical trials and outcome research. ${ }^{35}$

\section{Statistical analysis}

In order to get a blind data analysis, the person performing the statistical analysis did not know which lens was assigned 
first. A descriptive analysis of all the variables studied was performed. Absolute frequency and percentage were obtained for categorical variables, whereas mean and standard deviation (SD) were calculated for continuous variables.

The prevalence of CVS and CVS-Q ${ }^{\mathcal{O}}$ score were calculated for each of the variables and categories. Changes in the prevalence of CVS between time points for each type of lens were evaluated using Cochran's $Q$ test, and multiple comparisons were performed using McNemar's test with Bonferroni correction. The differences in the prevalence of CVS at each time point between lenses were evaluated using McNemar's test. Bonferroni test was applied to evaluate changes in CVS- $\mathrm{Q}^{\odot}$ score between time points for each type of lens, and the differences in CVS- ${ }^{\mathcal{C}}$ score at each time point between lenses were evaluated using the Student $t$ test. In addition, the prevalence of the 16 symptoms included in the CVS- $\mathrm{Q}^{\mathscr{C}}$ was calculated at $\mathrm{T} 0, \mathrm{~T} 3$ and $\mathrm{T}^{\prime} 3$, and the differences evaluated using McNemar's test.

In order to identify the factors associated with decreased CVS while wearing occupational lenses with respect to those when wearing PALs, the difference between the CVS$\mathrm{Q}^{\mathcal{O}}$ scores (T3- $\mathrm{T}^{\prime} 3$ ) was calculated; a decrease $\geq 2$ points in CVS- ${ }^{\odot}$ score between $\mathrm{T} 3$ and $\mathrm{T}^{\prime} 3$ was considered clinically significant. A 2 point decrease might mean that a person stops suffering a symptom that previously had been graded as often or always and intensely suffered; two symptoms that previously had been graded as often or always and moderately suffered or two symptoms that previously had been suffered occasionally and intensely.

The magnitude of the bivariate associations of the decrease in CVS- $\mathrm{Q}^{\odot}$ score $\geq 2$ points with the explanatory variables were calculated using crude odds ratio (cOR), and their confidence interval at $95 \%(95 \%$ CI $)$ estimated by binary logistic regression models. The explanatory variables that show a slight association $(p<0.1)$ with an improvement $\geq 2$ points of CVS-Q ${ }^{\odot}$ score in the bivariate analysis were selected to be included in a multivariate logistic model estimating the adjusted odds ratio (aOR) and its 95\% CI. A $p$-value $<0.05$ was considered statistically significant. IBM SPSS Statistics version 24 (IBM Corp.ibm.com) and R version 3.5.1 ( $\mathrm{R}$ core Team, r-project.org) were used for the analysis.

\section{Results}

The final sample was composed of 69 digital device workers (Table 1), with six losses to follow-up. The mean (SD) age was 54.7 (5.0) years (range: $46-69$ ), and $37.7 \%$ were female. The mean (SD) digital device use at work was 6.5 (1.3) hours/day (range: 4-10) and for 23.1 (5.8) years (range: 835). $92.8 \%$ did not have scheduled breaks and $53.6 \%$ had a maximum continuous work time $>1 \mathrm{~h}$. All workers used desktop computers at their workplace. The mean (SD) total digital device use (work and leisure time) was 8.6 (1.9) hours/day (range: $4.7-13.0$ ). There were $78.3 \%$ ametropes and $65.2 \%$ advanced presbyopes.

The equivalent sphere $(\mathrm{M})$ was close to $-1.00 \mathrm{D}$, and the overall defocus (B) was approximately $2.50 \mathrm{D}$ in each eye, both with their usual spectacles and after refraction. Statistically significant differences between the usual spectacles and the refractive error determined by the optometrist were found for $\mathrm{M}$ in the right eye $(p=0.03)$ and for $\mathrm{J}_{0}$ in both

Table 1. Sociodemographic, occupational, digital device exposure and refractive characteristics of the sample

\begin{tabular}{|c|c|c|}
\hline & $n$ & $\%$ \\
\hline Total & 69 & 100.0 \\
\hline \multicolumn{3}{|l|}{ Age (years) } \\
\hline $46-50$ & 15 & 21.7 \\
\hline $51-52$ & 10 & 14.5 \\
\hline $53-55$ & 21 & 30.4 \\
\hline $56-69$ & 23 & 33.3 \\
\hline \multicolumn{3}{|l|}{ Sex } \\
\hline Male & 43 & 62.3 \\
\hline Female & 26 & 37.7 \\
\hline \multicolumn{3}{|l|}{ Job category } \\
\hline AS & 32 & 46.4 \\
\hline TRS & 37 & 53.6 \\
\hline \multicolumn{3}{|c|}{ Digital device use at work (hours/day) } \\
\hline $4-6$ & 33 & 47.8 \\
\hline$>6$ & 36 & 52.2 \\
\hline \multicolumn{3}{|c|}{ Digital device use at work (days/week) } \\
\hline 5 & 49 & 71.0 \\
\hline 6 & 16 & 23.2 \\
\hline 7 & 4 & 5.8 \\
\hline \multicolumn{3}{|c|}{ Digital device use at work (years) } \\
\hline$\leq 20$ & 25 & 36.2 \\
\hline $21-29$ & 31 & 44.9 \\
\hline$\geq 30$ & 13 & 18.8 \\
\hline \multicolumn{3}{|c|}{ Maximum continuous work time at the digital devices (minutes) } \\
\hline$\leq 60$ & 32 & 46.4 \\
\hline $61-120$ & 28 & 40.6 \\
\hline$>120$ & 9 & 13.0 \\
\hline \multicolumn{3}{|c|}{ Scheduled breaks during digital device work } \\
\hline Yes & 5 & 7.2 \\
\hline No & 64 & 92.8 \\
\hline \multicolumn{3}{|c|}{ Total use of digital devices (hours/day) } \\
\hline$\leq 7.5$ & 24 & 34.8 \\
\hline $7.6-10$ & 32 & 46.4 \\
\hline$>10$ & 13 & 18.8 \\
\hline \multicolumn{3}{|l|}{ Ametropia } \\
\hline No & 15 & 21.7 \\
\hline Yes & 54 & 78.3 \\
\hline \multicolumn{3}{|l|}{ Presbyopia } \\
\hline Moderate & 24 & 34.8 \\
\hline Advanced & 45 & 65.2 \\
\hline
\end{tabular}

AS, Administrative Staff; TRS, Teaching and Research Staff. 
eyes $(p<0.001)$, as well as in the near addition $(p<0.001)$. Differences were also found for both distance $(p<0.001)$ and near $(p=0.002)$ visual acuity. There were $52.2 \%$ myopes and $26.1 \%$ hyperopes; six workers with mild and three with severe anisometropia (the latter not exceeding 3.25D) (Appendix S1).

Table 2 shows the prevalence of CVS at different time points. At T0, $68.1 \%$ suffered CVS; after three months of PAL use, the prevalence decreased to $33.3 \%$; after three months of occupational lens use, CVS decreased to $18.8 \%$ $(p<0.001)$. There were also significant differences when comparing CVS prevalence measured with each lens design at the same time point: at 1 week $\left(\mathrm{T} 1-\mathrm{T}^{\prime} 1, p<0.001\right)$, at 1 month (T2-T' $2, p<0.001)$ and at 3 months (T3-T' 3 , $p=0.01)$. No significant differences were found in the prevalence of CVS over the period of use for each type of lens.

With both PALs and occupational lenses, the CVS-Q ${ }^{\odot}$ scores decreased with respect to T0 $(p \leq 0.001)$; this decrease was greater with the occupational lenses. CVS-Q ${ }^{\complement}$ score was lower with occupational lenses versus PALs at all time points $(p \leq 0.001)$ (Figure 2$)$. Again, no statistically significant differences were found in the CVS-Q ${ }^{\odot}$ score

Table 2. Prevalence of computer vision syndrome (CVS), differences between time points for each type of lens and differences between lenses ( $p$-value)

\begin{tabular}{|c|c|c|c|c|c|c|c|}
\hline PALs & $n$ & $\%$ & \multicolumn{2}{|c|}{ Cochran's $Q$ test } & $\mathrm{T}^{\dagger}$ & $\mathbf{T 2}^{\dagger}$ & $\mathbf{T 3}^{+}$ \\
\hline TO & 47 & 68.1 & \multirow{4}{*}{\multicolumn{2}{|c|}{$<0.001 *$}} & \multirow[t]{4}{*}{$0.004 *$} & $0.003 *$ & $<0.001 *$ \\
\hline $\mathrm{T} 1$ & 32 & 46.4 & & & & 1.000 & 0.06 \\
\hline $\mathrm{T} 2$ & 31 & 44.9 & & & & & 0.04 \\
\hline T3 & 23 & 33.3 & & & & & \\
\hline \multicolumn{3}{|c|}{$\begin{array}{l}\text { Occupational } \\
\text { lenses }\end{array}$} & & $T^{\prime} \mathbf{1}^{\dagger}$ & & $\mathbf{T}^{\prime} \mathbf{2}^{\dagger}$ & $\mathbf{T}^{\prime} \mathbf{3}^{\dagger}$ \\
\hline TO & 47 & 68.1 & $<0.001 *$ & $<0$ & $01 *$ & $<0.001 *$ & $<0.001 *$ \\
\hline$T^{\prime} 1$ & 9 & 13.0 & & & & 0.55 & 0.22 \\
\hline $\mathrm{T}^{\prime} 2$ & 12 & 17.4 & & & & & 1.00 \\
\hline$T^{\prime} 3$ & 13 & 18.8 & & & & & \\
\hline
\end{tabular}

PALs -

\begin{tabular}{llll}
$\begin{array}{l}\text { Occupational } \\
\text { lenses }\end{array}$ & $\mathbf{T}^{\prime} \mathbf{1}^{*}$ & $\mathbf{T}^{\prime} \mathbf{2}^{*}$ & $\mathbf{T}^{\prime} \mathbf{3}^{*}$ \\
\hline T1 & $<0.001^{* *}$ & & \\
T2 & & $<0.001^{* *}$ & \\
T3 & & & $0.013^{* *}$
\end{tabular}

PALs, progressive addition lenses.

${ }^{\dagger}$ McNemar's test with Bonferroni correction: significant

$p$-value $<0.008$.

${ }^{ \pm}$McNemar's test.

$* p$-value $<0.008$.

$* * p$-value $<0.05$ over the period using PALs (T1-T3, $p=0.06)$ and occupational lenses $\left(\mathrm{T}^{\prime} 1-\mathrm{T}^{\prime} 3, p=0.17\right)$.

Table 3 shows that at T0 the prevalence of symptoms was higher, finding statistically significant differences in almost all symptoms when comparing T0 versus $\mathrm{T} 3$ and $\mathrm{T} 0$ versus $T^{\prime} 3$. In addition, the prevalence of most symptoms decreased from $\mathrm{T} 3$ to $\mathrm{T}^{\prime} 3$, with these differences being statistically significant for itching (from $56.5 \%$ to $36.2 \%$, $p=0.007$ ), blurred vision (from $47.8 \%$ to $29.0 \%, p=0.01$ ) and difficulty focusing for near vision (from $49.3 \%$ to $31.9 \%, p=0.04)$.

It was found that $55.1 \%$ of the sample improved their CVS-Q ${ }^{\odot}$ score after wearing occupational lenses; $40.6 \%$ of the sample improved $\geq 2$ points (Appendix S2). In the bivariate analysis (Table 4) it was observed that females were three times more likely to have this improvement of two points or more $(\mathrm{OR}=3.15 ; 95 \% \mathrm{CI}, 1.14-8.68$; $p=0.03$ ). However, having a distance refractive error (i.e., being ametropic), made this improvement less likely $(\mathrm{OR}=0.25$; 95\% CI, 0.07-0.84; $p=0.03$ ).

The multivariate analysis, after adjusting for sex, digital device use at work (hours/day), ametropia and presbyopia indicated that ametropia was associated with a CVS-Q ${ }^{(}$ score improvement $\geq 2$ points between $\mathrm{T} 3-\mathrm{T}^{\prime} 3$ (Table 5 ). Ametropes had a lower likelihood of improving than emmetropes $(\mathrm{OR}=0.27, p=0.05)$.

A total of $89.8 \%$ of digital device workers were satisfied or very satisfied with the occupational lenses, and $71 \%$ with PALs. None of the workers were very dissatisfied with the occupational lenses (Appendix S3A). Although the adaptation time was short for both designs, adaptation was faster with the occupational lenses; $50.7 \%$ adapted instantly, and $26.1 \%$ adapted in a few hours. Only $13.0 \%$ and $5.8 \%$ of the sample did not manage to adapt to the PALs and to the occupational lenses, respectively (Appendix S3B). $73.9 \%$ of workers chose the occupational lenses as their first choice for digital device work, $17.4 \%$ chose PALs and $8.7 \%$ chose their usual spectacles.

\section{Discussion}

The results of this study indicate a statistically significant decrease in the prevalence of CVS and in the CVS- ${ }^{\odot}$ score when digital device workers use occupational lenses instead of PALs. This improvement was less likely in ametropes than emmetropes after three months of adaptation to both lenses, and it was not associated with the level of presbyopia, hours per day of digital device use at work nor sex. Almost all digital device workers showed great satisfaction with the use of occupational lenses, choosing them as their preferred option for work.

There are several studies that evaluated self-perceived symptomatology in digital device workers through 


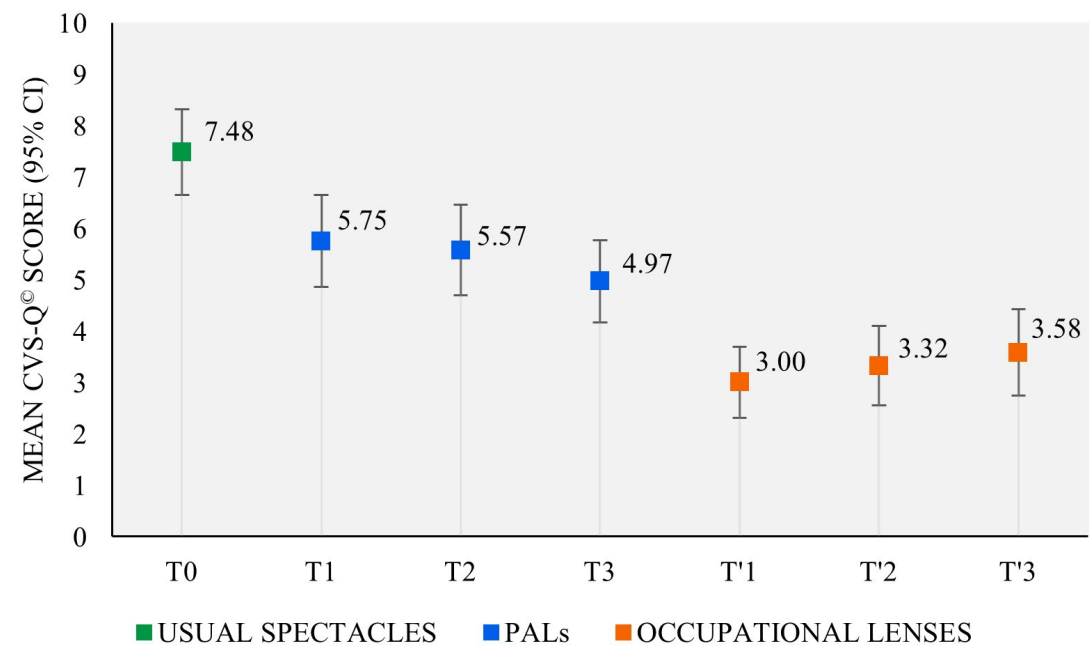

Figure 2. Mean CVS-Q ${ }^{\mathcal{O}}$ scores at baseline (T0), 1 week (T1, $\left.T^{\prime} 1\right), 1$ month $\left(T 2, T^{\prime} 2\right)$ and 3 months $\left(T 3, T^{\prime} 3\right)$ after wearing each lens. PALs: progressive addition lenses. 95\% Cl: 95\% confidence interval.

Table 3. Prevalence of symptoms and differences after three months wearing progressive addition lenses (PALs) (T3) and occupational lenses ( $T^{\prime} 3$ )

\begin{tabular}{|c|c|c|c|c|c|c|c|c|c|}
\hline & \multicolumn{2}{|l|}{ T0 } & \multicolumn{2}{|l|}{ T3 } & \multicolumn{2}{|l|}{$\mathbf{T}^{\prime} \mathbf{3}$} & \multirow{2}{*}{$\begin{array}{l}\text { T0 vs. T3 } \\
p \text {-value }{ }^{\dagger}\end{array}$} & \multirow{2}{*}{$\begin{array}{l}\text { T0 vs. } T^{\prime} 3 \\
p \text {-value }\end{array}$} & \multirow{2}{*}{$\begin{array}{l}\text { T3 vs. } T^{\prime} 3 \\
p \text {-value }{ }^{\dagger}\end{array}$} \\
\hline & $n$ & $\%$ & $n$ & $\%$ & $n$ & $\%$ & & & \\
\hline Burning & 16 & 23.2 & 14 & 20.3 & 11 & 15.9 & 0.77 & 0.30 & 0.58 \\
\hline Itching & 51 & 73.9 & 39 & 56.5 & 25 & 36.2 & $0.02 *$ & $<0.001 *$ & $0.007 *$ \\
\hline Feeling of a foreign body & 25 & 36.2 & 11 & 15.9 & 13 & 18.8 & $0.003 *$ & $0.01 *$ & 0.80 \\
\hline Tearing & 31 & 44.9 & 22 & 31.9 & 20 & 29.0 & 0.08 & $0.04 *$ & 0.77 \\
\hline Excessive blinking & 32 & 46.4 & 18 & 26.1 & 10 & 14.5 & $0.004 *$ & $<0.001 *$ & 0.08 \\
\hline Eye redness & 37 & 53.6 & 23 & 33.3 & 17 & 24.6 & $0.003 *$ & $0.001 *$ & 0.24 \\
\hline Eye pain & 20 & 29.0 & 11 & 15.9 & 11 & 15.9 & $0.02 *$ & $0.02 *$ & 1.00 \\
\hline Heavy eyelids & 24 & 34.8 & 22 & 31.9 & 12 & 17.4 & 0.82 & $0.01 *$ & 0.05 \\
\hline Dryness & 35 & 50.7 & 31 & 44.9 & 25 & 36.2 & 0.52 & $0.03 *$ & 0.21 \\
\hline Blurred vision & 43 & 62.3 & 33 & 47.8 & 20 & 29.0 & 0.06 & $<0.001 *$ & $0.01 *$ \\
\hline Double vision & 8 & 11.6 & 8 & 11.6 & 3 & 4.4 & 1.00 & 0.13 & 0.13 \\
\hline Difficulty focusing for near vision & 52 & 75.4 & 34 & 49.3 & 22 & 31.9 & $0.001 *$ & $<0.001 *$ & $0.04 *$ \\
\hline Increased sensitivity to light & 35 & 50.7 & 19 & 27.5 & 14 & 20.3 & $0.003^{*}$ & $<0.001 *$ & 0.18 \\
\hline Coloured halos around objects & 13 & 18.8 & 4 & 5.8 & 3 & 4.4 & $0.04 *$ & $0.01 *$ & 1.00 \\
\hline Feeling that sight is worsening & 46 & 66.7 & 25 & 36.2 & 17 & 24.6 & $<0.001 *$ & $<0.001 *$ & 0.12 \\
\hline Headache & 26 & 37.7 & 19 & 27.5 & 20 & 29.0 & 0.12 & 0.26 & 1.00 \\
\hline
\end{tabular}

'McNemar's test.

${ }^{*} p$-value $<0.05$.

questionnaires comparing PALs and occupational lenses. However, most questionnaires are unvalidated and do not provide information about a global construct but rather individual assessments of each symptom. Only Cagnie et $a l .{ }^{36}$ used the validated Visual Fatigue Questionnaire (VFQ) for the measurement of visual fatigue. In that study, participants $(n=35)$ were randomised into two groups (either wearing PALs or occupational lenses) with a follow-up of six months. Although the mean VFQ score was lower in the group that wore occupational lenses in all cases, the observed differences were not statistically significant $(p=0.14)$. However, there were significant differences in adaptation over time $(p=0.003)$. In the present study, the adaptation period to the new lenses did not affect CVS, whereas Cagnie et al. detected less visual fatigue at the end of this period. It must be taken into account that the present study only included digital device workers that previously used PALs, and therefore were used to wearing them. Cagnie et al. included digital device workers that previously wore lenses for myopia or hyperopia, or even subjects that 
Table 4. Percentage of workers with improvement $\geq 2$ points of the mean CVS- $Q^{\odot}$ score from T3 to $T^{\prime} 3$ and association with sociodemographic, occupational, digital device exposure and refractive factors

\begin{tabular}{|c|c|c|c|c|c|}
\hline Mean & & SD & cOR & $95 \% \mathrm{Cl}$ & $\begin{array}{l}p- \\
\text { value }\end{array}$ \\
\hline \multicolumn{6}{|l|}{ Age (years) } \\
\hline \multirow[t]{2}{*}{53.5} & & 4.5 & 0.92 & $\begin{array}{r}0.83- \\
1.02\end{array}$ & 0.12 \\
\hline & $n$ & $\%$ & COR & $95 \% \mathrm{Cl}$ & $p$-value \\
\hline \multicolumn{6}{|l|}{ Sex } \\
\hline Male & 13 & 30.2 & 1 & & \\
\hline Female & 15 & 57.7 & 3.15 & $1.14-8.68$ & $0.03 * *$ \\
\hline \multicolumn{6}{|l|}{ Job category } \\
\hline AS & 15 & 46.9 & 1 & & \\
\hline TRS & 13 & 35.1 & 0.61 & $0.23-1.62$ & 0.32 \\
\hline \multicolumn{6}{|c|}{ Digital device use at work (hours/day) } \\
\hline $4-6$ & 10 & 30.3 & 1 & & \\
\hline$>6$ & 18 & 50.0 & 2.30 & $0.86-6.18$ & $0.01 *$ \\
\hline \multicolumn{6}{|c|}{ Digital device use at work (days/week) } \\
\hline 5 & 19 & 38.8 & 1 & & \\
\hline 6 & 9 & 56.3 & 2.03 & $0.65-6.37$ & 0.23 \\
\hline 7 & 0 & 0.0 & - & - & - \\
\hline \multicolumn{6}{|c|}{ Digital device use at work (years) } \\
\hline$\leq 20$ & 13 & 52.0 & 1 & & \\
\hline $21-29$ & 10 & 32.3 & 0.44 & $0.15-1.30$ & 0.14 \\
\hline$\geq 30$ & 5 & 38.5 & 0.58 & $0.15-2.26$ & 0.43 \\
\hline \multicolumn{6}{|c|}{ Maximum continuous work time at the digital devices (minutes) } \\
\hline$\leq 60$ & 15 & 46.9 & 1 & & \\
\hline $61-120$ & 9 & 32.1 & 0.54 & $0.19-1.54$ & 0.25 \\
\hline$>120$ & 4 & 44.4 & 0.91 & $0.21-4.01$ & 0.90 \\
\hline \multicolumn{6}{|c|}{ Scheduled breaks during digital device work } \\
\hline Yes & 2 & 40.0 & 1 & & \\
\hline No & 26 & 40.6 & 1.03 & $0.16-6.58$ & 0.98 \\
\hline \multicolumn{6}{|c|}{ Total use of digital devices (hours/day) } \\
\hline$\leq 7.5$ & 8 & 33.3 & 1 & & \\
\hline $7.6-10$ & 13 & 40.6 & 1.37 & $0.45-4.13$ & 0.58 \\
\hline$>10$ & 7 & 53.8 & 2.33 & $0.59-9.29$ & 0.23 \\
\hline \multicolumn{6}{|l|}{ Ametropia } \\
\hline No & 10 & 66.7 & 1 & & \\
\hline Yes & 18 & 33.3 & 0.25 & $0.07-0.84$ & $0.03 * *$ \\
\hline \multicolumn{6}{|l|}{ Presbyopia } \\
\hline Moderate & 13 & 54.2 & 1 & & \\
\hline Advanced & 15 & 33.3 & 0.42 & $0.15-1.17$ & 0.10 \\
\hline
\end{tabular}

SD, standard deviation; COR, crude odds ratio; $95 \% \mathrm{Cl}, 95 \%$ confidence interval; AS, Administrative Staff; TRS, Teaching and Research Staff.

$* p$-value $<0.1$

$* * p$-value $<0.05$

did not wear a correction, which could have influenced their results.

Kolbe and Deble ${ }^{37}$ found that CVS was perceived approximately seven times more often with PALs compared with occupational lenses. Blurred vision was one of the symptoms that decreased the most with occupational lenses compared with PALs (46.8\% versus 5.8\%), which is
Table 5. Multivariate logistic regression model for the improvement in $\geq 2$ points of the mean $\mathrm{CVS}-\mathrm{Q}^{\circ}$ score from $\mathrm{T} 3$ to $\mathrm{T}^{\prime} 3$

\begin{tabular}{llll}
\hline & aOR & $95 \% \mathrm{Cl}$ & $\boldsymbol{p}$-value \\
\hline $\begin{array}{l}\text { Sex } \\
\text { Male }\end{array}$ & 1 & & \\
Female & 2.64 & $0.88-7.92$ & 0.08 \\
$\begin{array}{l}\text { Digital device } \\
4-6\end{array}$ & 1 & \\
$>6$ & 2.01 & $0.67-5.97$ & 0.21 \\
$\begin{array}{l}\text { Ametropia } \\
\text { No }\end{array}$ & 1 & & \\
Yes & 0.27 & $0.07-1.00$ & $0.05 *$ \\
$\begin{array}{l}\text { Presbyopia } \\
\text { Moderate }\end{array}$ & 1 & & \\
Advanced & 0.41 & $0.14-1.24$ & 0.12 \\
\hline $\begin{array}{l}\text { aOR, adjusted odds ratio; } 95 \% \mathrm{Cl} \text {, } 95 \% \text { confidence interval. } \\
\text { * } p \text {-value }<0.05 .\end{array}$ &
\end{tabular}

consistent with our results $(47.8 \%$ vs $29.0 \%, p=0.01)$. Notably, that study used an unvalidated questionnaire and did not specify how the CVS global score was calculated. The participants $(n=190)$ were previous PAL or occupational lens users who used each of the lenses for two weeks (less than the three months in the present study), and the lens designs were from three different companies. Additionally, in the Kolbe and Deble study subjects received their first spectacles in a randomised and masked manner, which was not the case here.

In the study by Jaschinski et al., ${ }^{14}$ presbyopic participants $(n=23)$ who habitually used PALs, occupational lenses and reading spectacles, wore each type of lens (PALs and occupational lenses) for two weeks in a double-masked, quasi-experimental procedure, with the purpose of evaluating ocular strain and headache using an unvalidated questionnaire. A higher score in both symptoms was seen with PALs compared with occupational lenses, but the differences were not statistically significant. Our results for headache showed a similar prevalence at $\mathrm{T} 3$ and $\mathrm{T}^{\prime} 3(p=1.00)$.

In addition, the present study showed a decrease in the prevalence of CVS after wearing the two designs for 1 week, compared with the baseline findings. This decrease, even with the PALs, whose design was a priori similar to the usual spectacles, could be attributed to the refractive adjustments made, in which higher additions $(p<0.001)$ and better distance $(p<0.001)$ and near $(p=0.002)$ visual acuity were obtained. Although the studies by Cagnie et al. ${ }^{36}$ and Kolbe and Deble ${ }^{37}$ also made refractive adjustments before fitting the new lenses (PALs and occupational lenses), they did not report the possible effects of this change on CVS.

In the present investigation, the improvement of $\geq 2$ points in the CVS-Q ${ }^{\mathcal{O}}$ score between $\mathrm{T} 3$ and $\mathrm{T}^{\prime} 3$ was associated with the refractive characteristics of each worker. 
Specifically, symptoms improved less with occupational lenses in ametropes than emmetropes. To the contrary, Kolbe and Deble ${ }^{37}$ found that ametropia did not influence the CVS score, noting that the mean difference of the scores between emmetropic and ametropic subjects with PALs or occupational lenses failed to show statistical significance. However, they considered those with $\mathrm{M}>-0.25 \mathrm{D}$ and $<+0.25 \mathrm{D}$ as emmetropes, while our criteria were less strict. Future studies should further investigate which refractive group (myopia, hyperopia or astigmatism) benefits the most from occupational lenses and from what specific correction.

With regard to differences in the prevalence of CVS with sex, Tauste et al. ${ }^{20}$ used the same questionnaire with public administration office workers and estimated that women were twice as likely as men to suffer CVS (prevalence of $61 \%$ vs $44 \%$; OR $=2.00, p<0.001$ ). In our case, similar sex differences were observed for both PALs and occupational lenses. The prevalence of CVS in women and men at T3 was $50 \%$ and $23.3 \%$, respectively. At $\mathrm{T}^{\prime} 3$, these results decreased to $26.9 \%$ and $14 \%$, respectively. Accordingly, the prevalence is reduced with occupational lenses in both sexes. The lower prevalence values observed here in both men and women may have occurred because contact lens wearers were excluded, while they constituted $21.6 \%$ of the sample studied by Tauste et al. ${ }^{20}$

When evaluating preference, Kolbe and Deble ${ }^{37}$ found that $84.6 \%$ chose occupational lenses for their working day, while Jaschinski et al. ${ }^{14}$ reported a percentage of $61 \%$. Our results showed an intermediate value of $73.9 \%$. Regarding satisfaction, Cagnie et al., ${ }^{36}$ found users of occupational lenses reported higher satisfaction with intermediate vision ( $p=0.001)$, while those who used PALs, were more satisfied with their distance vision $(p<0.001)$. These results coincide with our findings, with a very high of level of satisfaction with occupational lenses (68.1\%). Comments regarding these lenses indicated that the design covered the demands of the workplace with digital devices, and that they provided greater sharpness and a wider field of view at intermediate-near distances without the need to move the head for better focus. However, there were also comments about the need to change spectacles to address distance vision demands, which could be uncomfortable in certain conditions, even though those workers who attended to the public were excluded from this study.

Regarding the limitations of this study, the design was not randomised nor masked, as was done in other investigations. ${ }^{14,37}$ We considered that masking was not possible due to the characteristics of the lenses studied. While PALs provide clear vision at all distances (they can be worn all day for a range of activities, e.g., for working and driving), occupational lenses should only be used for intermediate and near distances. Therefore, workers could not be masked since the instructions for use varied according to the optical design, as well as the visual perception of the environment. In fact, as noted by Jaschinski et al., 'It was almost inevitable that participants noticed the blurred distance vision with the computer vision PALs, which can occur when looking outside the window. These conditions cannot be avoided if realistic office conditions are to be investigated. $^{, 14}$

Another limitation was the small sample size in the multivariate analysis that included only workers who improved $\geq 2$ points in CVS-Q ${ }^{\odot}$ scores $(n=28)$. Therefore, this is a pilot study that can be considered as a good starting point for other investigations. The calculated odds ratios indicate statistical trends that could become significant if the sample size were increased. Future studies should investigate whether women and those workers most exposed to digital devices are more likely to improve with occupational lenses, as well as whether advanced presbyopes improve less with these lenses. CVS symptoms in advanced presbyopes may be due to other factors such as a shorter tear break up time and thinner tear lipid layer ${ }^{7,18,38,39}$ which would not change with the design of the progressive lens. It should also be investigated whether different results might be found for other types of digital devices (such as laptop computers or tablets), since all the workers tested here used desktop computers at their workplace.

Some strengths of this study are discussed below. This is the first study to analyse the relationship between CVS and two types of ophthalmic progressive lenses in presbyopic digital device workers through a validated questionnaire (CVS$\left.\mathrm{Q}^{(}\right)$, providing reliability to our findings. Unlike other studies $^{14}$ that took measurements using the current refractive status of the worker (with possible uncorrected refractive error), an refraction was provided to improve the visual status, ${ }^{40}$ before the lens adaptation period. Likewise, to minimise the period of lens adaptation that could influence the results, only workers already using PALs were chosen, unlike other studies. $^{36,37}$ Finally, prevention technical briefings about workplace hazards in the University, including data on the air temperature, relative humidity and illumination were consulted, verifying that the workplaces complied with the current regulations $^{41-43}$ for sedentary jobs typical of offices with high/very high visual requirements. Thus, we ensured that these external factors did not influence our results.

To conclude, the self-perceived ocular and visual symptomatology of presbyopic digital device workers indicated that they preferred occupational lenses to PALs in their workplace, particularly if they were emmetropic. These results, together with the optical advantages of occupational lenses having a wider visual field, may guide eye care professionals to recommend the most appropriate optical design for the needs of the workplace, and provide better care to digital device workers. 


\section{Acknowledgements}

This work was supported by grants from the Department of Education, Research, Culture and Sports, Valencian Government (GV/2017/187).

\section{Conflict of interest}

The authors report no conflicts of interest and have no proprietary interest in any of the materials mentioned in this article.

\section{Author contributions}

Mar Sánchez-Brau: Formal analysis (lead); Investigation (lead); Visualization (equal); Writing-original draft (lead); Writing-review \& editing (equal). Begoña DomenechAmigot: Conceptualization (supporting); Formal analysis (supporting); Investigation (supporting); Methodology (equal); Resources (equal); Supervision (supporting); Visualization (equal); Writing-original draft (supporting); Writing-review \& editing (equal). Francisco BrocalFernández: Conceptualization (supporting); Formal analysis (supporting); Methodology (equal); Resources (equal); Supervision (supporting); Writing-original draft (supporting); Writing-review \& editing (equal). Mar Seguí-Crespo: Conceptualization (lead); Formal analysis (lead); Funding acquisition (lead); Investigation (supporting); Methodology (equal); Project administration (lead); Resources (equal); Supervision (lead); Visualization (equal); Writingoriginal draft (lead); Writing-review \& editing (equal).

\section{References}

1. Eurofound. Sixth European Working Conditions SurveyOverview report (2017 update). Publications Office of the European Union: Luxembourg, 2017. Available at: eurof ound.europa.eu/sites/default/files/ef_publication/field_ef_d ocument/ef1634en.pdf. Accessed September 14, 2020

2. Gowrisankaran $S \&$ Sheedy JE. Computer vision syndrome: A review. Work 2015; 52: 303-314.

3. Parihar JKS, Jain VK, Chaturvedi $\mathrm{P}$ et al. Computer and visual display terminals (VDT) vision syndrome (CVDTS). Med J Armed Forces India 2016; 72: 270-276.

4. Fenga C, Aragona P, Di Nola C \& Spinella R. Comparison of ocular surface disease index and tear osmolarity as markers of ocular surface dysfunction in video terminal display workers. Am J Ophthalmol 2014; 158: 41-48.e2.

5. Yazici A, Sari ES, Sahin G et al. Change in tear film characteristics in visual display terminal users. Eur J Ophthalmol 2015; 25: 85-89.

6. Blehm C, Vishnu S, Khattak A, Mitra S \& Yee RW. Computer vision syndrome: a review. Surv Ophthalmol 2005; 50: 253-262.
7. Rosenfield M. Computer vision syndrome: a review of ocular causes and potential treatments. Ophthalmic Physiol Opt 2011; 31: 502-515.

8. Coles-Brennan C, Sulley A \& Young G. Management of digital eye strain. Clin Exp Optom 2019; 102: 18-29.

9. Ye Z, Honda S, Abe Y et al. Influence of work duration or physical symptoms on mental health among Japanese visual display terminal users. Ind Health 2007; 45: 328-333.

10. Tamez González S, Ortiz-Hernández L, Martínez-Alcántara S \& Méndez-Ramírez I. Riesgos y daños a la salud derivados del uso de videoterminal. Salud Publica Mex 2003; 45: 171180.

11. Mocci F, Serra A \& Corrias GA. Psychological factors and visual fatigue in working with video display terminals. Occup Environ Med 2001; 58: 267-271.

12. Woods V. Musculoskeletal disorders and visual strain in intensive data processing workers. Occup Med 2005; 55: 121-127.

13. Bhanderi DJ, Choudhary S \& Doshi VG. A communitybased study of asthenopia in computer operators. Indian J Ophthalmol 2008; 56: 51-55.

14. Jaschinski W, König M, Mekomtso TM, Ohlendorf A \& Welscher M. Comparison of progressive addition lenses for general purpose and for computer vision: an office field study. Clin Exp Optom 2015; 98: 234-243.

15. Mowatt L, Gordon C, Santosh ABR \& Jones T. Computer vision syndrome and ergonomic practices among undergraduate university students. Int J Clin Pract 2018; 72: 1-7.

16. Munshi S, Varghese A \& Dhar-Munshi S. Computer vision syndrome-A common cause of unexplained visual symptoms in the modern era. Int J Clin Pract 2017; 71: e12962. Available at: onlinelibrary.wiley.com/doi/abs/10.1111/ijcp. 12962. Accessed September 14, 2020.

17. Argilés M, Cardona G, Pérez-Cabré E \& Rodríguez M. Blink rate and incomplete blinks in six different controlled hardcopy and electronic reading conditions. Invest Ophthalmol Vis Sci 2015; 56: 6679-6685.

18. Guillon M \& Maïssa C. Tear film evaporation - effect of age and gender. Cont Lens Anterior Eye 2010; 33: 171-175.

19. Ranasinghe P, Wathurapatha WS, Perera YS et al. Computer vision syndrome among computer office workers in a developing country: an evaluation of prevalence and risk factors. BMC Res Notes 2016; 9: 150. Available at: bmcresnotes.b iomedcentral.com/articles/10.1186/s13104-016-1962-1? optIn=false. Accessed September 14, 2020.

20. Tauste A, Ronda E, Molina MJ \& Seguí MM. Effect of contact lens use on Computer Vision Syndrome. Ophthalmic Physiol Opt 2016; 36: 112-119.

21. Sánchez-Brau M, Domenech-Amigot B, Brocal-Fernández F, Quesada-Rico JA \& Seguí-Crespo M. Prevalence of Computer Vision Syndrome and its relationship with ergonomic and individual factors in presbyopic VDT workers using progressive addition lenses. Int J Environ Public Health 2020; 17: 1003. Available at: mdpi.com/1660-4601/17/3/1003. Accessed September 14, 2020. 
22. Mancil GL, Bailey IL, Campbell JB et al. Care of the patient with presbyopia. Reference guide for clinicians. American Optometric Association: St. Louis; 2011. Available at: sdeye s.org/docs/CPG-17.pdf. Accessed February 7, 2021.

23. Butzon SP, Sheedy JE \& Nilsen E. The efficacy of computer glasses in reduction of computer worker symptoms. Optometry 2002; 73: 221-230.

24. Allie P, Kokot D, Purvis C \& Bartha MC. Computer Display Placement for progressive addition lens wearers: a field observation of multiple display conditions. Proc Hum Fact Ergonom Soc Annu Meeting 2009; 53: 493-497.

25. Weidling $\mathrm{P} \&$ Jaschinski $\mathrm{W}$. The vertical monitor position for presbyopic computer users with progressive lenses: how to reach clear vision and comfortable head posture. Ergonomics 2015; 58: 1813-1829.

26. Des Jarlais DC, Lyles C, Crepaz N, Trend Group. Improving the reporting quality of nonrandomized evaluations of Behavioral and public health interventions: the TREND statement. Am J Public Health 2004; 94: 361-366.

27. Faul F, Erdfelder E, Lang A \& Buchner A. G*Power 3: A flexible statistical power analysis program for the social, behavioural, and biomedical sciences. Behav Res Methods 2007; 39: 175-191.

28. Erdfelder E, Faul F, Buchner A \& Lang A. Statistical power analyses using $\mathrm{G}^{*}$ Power 3.1: Tests for correlation and regression analyses. Behav Res Methods 2009; 41: 1149-1160.

29. INSST, Instituto Nacional de Seguridad y Salud en el Trabajo. Guía técnica de evaluación y prevención de los riesgos relativos a la utilización de equipos con pantallas de visualización. Ministerio de Trabajo y Asuntos Sociales: Madrid; 2006. Available at: insst.es/documents/94886/96076/pantalla s/e3401950-f95d-4b89-b196-49c7c514bfa4. Accessed September 14, 2020.

30. Thibos LN, Wheeler W \& Horner D. Power vectors: an application of Fourier analysis to the description and statistical analysis of refractive error. Optom Vis Sci 1997; 74: 367-375.

31. Williams KM, Verhoeven VJ, Cumberland P et al. Prevalence of refractive error in Europe: the European Eye Epidemiology (E(3)) Consortium. Eur J Epidemiol 2015; 30: 305-315.

32. Linke SJ, Richard G \& Katz T. Prevalence and associations of anisometropia with spherical ametropia, cylindrical power, age, and sex in refractive surgery candidates. Invest Ophthalmol Vis Sci 2011; 52: 7538-7547.

33. Wei S, Sun Y, Li S et al. Refractive error in university students in central China: The Anyang University Students Eye Study. Invest Ophthalmol Vis Sci 2018; 59: 4691-4700.

34. Hagen LA, Gjelle JVB, Arnegard S et al. Prevalence and possible factors of myopia in Norwegian adolescents. Sci Rep
2018; 8: 13479. Available at: nature.com/articles/s41598018-31790-y. Accessed April 23, 2021

35. Seguí MM, Cabrero-García J, Crespo A, Verdú J \& Ronda E. A reliable and valid questionnaire was developed to measure computer vision syndrome at the workplace. J Clin Epidemiol 2015; 38: 662-673.

36. Cagnie B, De Meulemeester K, Saeys L et al. The impact of different lenses on visual and musculoskeletal complaints in VDU workers with work-related neck complaints: a randomized controlled trial. Environ Health Prev Med 2017; 22: 8. Available at: link.springer.com/article/10.1186/s12199017-0611-1. Accessed April 23, 2021.

37. Kolbe O \& Deble S. Presbyopic personal computer work: a comparison of progressive addition lenses for general purpose and personal computer work. Optom Vis Sci 2018; 95: 1046-1053.

38. Gayton JL. Etiology, prevalence, and treatment of dry eye disease. Clin Ophthalmol 2009; 3: 405-412.

39. Maïssa C \& Guillon M. Tear film dynamics and lipid layer characteristics- Effect of age and gender. Cont Lens Anterior Eye 2010; 33: 176-182.

40. Heus P, Verbeek JH \& Tikka C. Optical correction of refractive error for preventing and treating eye symptoms in computer users. Cochrane Database Syst Rev 2018; 4: CD009877.

41. Council Directive 89/654/EEC of 30 November 1989 concerning the minimum safety and health requirements for the workplace. Off J Eur Communities. L 393: 1-12. Available at: eurlex.europa.eu/eli/dir/1989/654/oj. Accessed September 14, 2020.

42. Council Directive 90/270/EEC of 29 May 1990 on the minimum safety and health requirements for work with display screen equipment. Off J Eur Communities. L 156: 14-18. Available at: eur-lex.europa.eu/eli/dir/1990/270/oj. Accessed September 14, 2020

43. Real Decreto 486/1997, de 14 de abril, por el que se establecen las disposiciones mínimas de seguridad y salud en los lugares de trabajo. BOE núm 97. Available at: boe.es/eli/es/rd/1997/ 04/14/486/con. Accessed September 14, 2020.

\section{Supporting Information}

Additional Supporting Information may be found in the online version of this article:

Appendix S1. Refractive characteristics of the sample. Appendix S2. Change of mean CVS-Q ${ }^{\circledR}$ score between T3-T'3.

Appendix S3. Personal satisfaction (A) and adaptation time (B) with the studied lenses. 